Vol. 24, No. 2, April 2021, hlm. 217-229

p-ISSN: 1410-9344; e-ISSN: 2549-5631

WARTA LPM

homepage: http://journals.ums.ac.id/index.php/warta

\title{
Pendampingan Promosi Digital SMA Muhammadiyah Piyungan untuk Meningkatkan Jumlah Pendaftar di Masa Pandemi COVID-19
}

\author{
${ }^{1}$ Erwan Sudiwijaya, ${ }^{2}$ Ayu Amalia \\ Prodi llmu Komunikasi, Universitas Muhammadiyah Yogyakarta

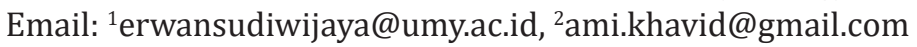

\section{Article Info}

Submitted: 28 September 2020

Revised: 16 December 2020

Accepted: 9 March 2021

Published: 21 April 2021

Keywords: Muhammadiyah Piyungan High School, Digital Promotion, Digital Marketing Communication
Kata kunci: SMU

Muhammadiyah Piyungan, Promosi Digital, Komunikasi Pemasaran Digital

\section{Abstract}

The emergence of the Minister of Education and Culture Regulation Number 51 of 2018 concerning PPDB (New Student Admission) in article 16 states that PPDB registration is carried out through zoning by $90 \%$ of capacity. This condition was coupled with the COVID-19 Pandemic which had a direct impact on the decline in the number of registrants at Muhammadiyah Piyungan High School, one of the causes of which was due to decreased physical promotional activities due to the imposition of physical restrictions. This has an impact on the decline in the number of registrants at Muhammadiyah Piyungan High School, currently the total number of students in 2019/2020 is 60 people. Therefore, the management teachers of SMA Muhammadiyah Piyungan took the initiative to change the format of their school so that it has a uniqueness, namely as a Muhammadiyah Boarding School and targeting a wider range of student targets, namely from outside the city. But still constrained in promoting digitally to prospective students and parents of students. In an effort to solve the partner problems that have been formulated above, we are planning a community service program that aims to develop a digital promotion strategy. The stages of community service methods carried out are 1) analysis of needs and situations; 2) planning and development of information systems; 3) introduction and training of information systems; and 4) evaluation of training results. This PKM activity produces an information system in the form of a website that is integrated with Instagram, increases the skills possessed by teachers and educators in managing and developing digital promotions and a set of All in One PCs as a supporting tool for managing digital promotions. Thus, it is expected that SMA MBS Muhammadiyah Piyungan can be more widely known and the demand for it will increase.

Abstrak
Kemunculan Peraturan Mendikbud Nomor 51 tahun 2018 tentang
PPDB (Penerimaan Peserta Didik Baru) pada pasal 16 menyebutkan
bahwa pendaftaran PPDB dilaksanakan melalui jalur zonasi sebesar


90\% dari daya tampung. Kondisi ini ditambah dengan Pandemi COVID-19 yang berdampak langsung pada menurunnya jumlah pendaftar di SMA Muhammadiyah Piyungan, salah satu penyebabnya ditengarai karena aktivitas promosi fisik yang menurun karena pemberlakukan pembatasan fisik. Hal ini berimbas pada menurunnya jumlah pendaftar di SMA Muhammadiyah Piyungan, saat ini total peserta didik di tahun 2019/2020 berjumlah 60 orang. Oleh karena itu guru-guru pengelola SMA Muhammadiyah Piyungan berinisiatif untuk mengubah format sekolah mereka agar memiliki kekhasan, yaitu sebagai Muhammadiyah Boarding School dan menyasar target siswa yang lebih luas yaitu dari luar kota. Namun masih terkendala dalam mempromosikan secara digital pada calon siswa dan orang tua siswa. Dalam upaya menyelesaikan permasalahan mitra yang sudah dirumuskan di atas, maka kami merencanakan program pengabdian masyarakat yang bertujuan untuk menyusun strategi promosi digital. Tahap-tahapan metode pengabdian masyarakat yang dilakukan adalah 1) analisis kebutuhan dan situasi; 2) perencanaan dan pengembangan sistem informasi; 3) pengenalan dan pelatihan sistem informasi; dan 4) evaluasi hasil pelatihan. Kegiatan PKM ini menghasilkan sebuah sistem informasi berupa website yang terintegrasi dengan instagram, peningkatan keahlian yang dimiliki oleh guru dan tenaga pendidik dalam mengelola dan mengembangkan promosi digital dan seperangkat PC All in One sebagai alat pendukung pengelolaan promosi digital. Dengan demikian diharapkan SMA MBS Muhammadiyah Piyungan dapat dikenal lebih luas dan peminatnya pun meningkat.

\section{PENDAHULUAN}

Kecamatan Piyungan berada di Kabupaten Bantul Yogyakarta memiliki luas wilayah 3.254,86 Ha. Dihuni oleh 10.177 KK dengan jumlah keseluruhan penduduk Kecamatan Piyungan adalah 37.814 orang, sebagian besar penduduknya adalah petani. Dari data monografi kecamatan tercatat 16.420 orang atau $43,4 \%$ penduduk Kecamatan Piyungan bekerja di sektor pertanian. Kecamatan Piyungan memiliki dua sekolah menengah atas yaitu SMA Negeri 1 Piyungan dan SMA Muhammadiyah Piyungan, serta empat sekolah menengah kejuruan yaitu SMK Budhi Dharma Piyungan, SMK Maarif 1 Piyungan, SMKS Maarif 2 Piyungan, dan SMK Muhammadiyah Piyungan.

SMA Muhammadiyah Piyungan sebagai satu-satunya SMA Swasta di Kecamatan Piyungan dikelola oleh enam guru dan pada semester gasal tahun pelajaran 2019/2020 ini mengasuh 66 siswa yang terdiri dari 31 siswa dan 35 siswi. Sekolah ini terletak di Mungur, Srimartani, Kec. Piyungan, Bantul, Daerah
Istimewa Yogyakarta 55792 dan berdiri di atas tanah seluas 3,292 meter persegi dan memiliki enam ruang kelas, satu ruang laboratorium, dan satu ruang perpustakaan.

Kemunculan Peraturan Mendikbud Nomor 51 tahun 2018 tentang PPDB (Penerimaan Peserta Didik Baru) pada pasal 16 menyebutkan bahwa pendaftaran PPDB dilaksanakan melalui tiga jalur yaitu: zonasi, prestasi, dan perpindahan tugas orang tua/wali. Jalur zonasi mensyaratkan batas kuota paling sedikit 90\% dari daya tampung sekolah. Jalur prestasi mensyaratkan batas paling banyak 5\% dari daya tampung sekolah. Jalur perpindahan tugas orang tua/wali mensyaratkan batas kuota paling banyak 5\% dari daya tampung sekolah (Kompasiana.com, 2019). Jalur pertama mengacu pada jarak rumah dan sekolah sehingga para siswa lebih memilih sekolah negeri karena saringan masuk tidak berdasarkan nilai hasil ujian (Kusdiyanto, 2020). Sistem zonasi ini memberikan dampak positif pada persebaran peserta didik yang merata di semua sekolah dan motivasi belajar yang 
meningkat di sekolah favorit di sisi sebaliknya kecumburuan sosial pun muncul sebagai dampak negatif (Wijayanti \& Nurjaman, 2020).

Dampak dari sistem zonasi pada penerimaan peserta didik baru bagi sekolah swasta adalah menurunnya jumlah pendaftar, hal ini jugalah yang dirasakan oleh SMA Muhammadiyah Piyungan. Satu tahun setelah peraturan ini diberlakukan memberikan dampak pada siswa yang hanya dua kelas, berdasarkan penuturan kepala sekolah SMA Muhammadiyah Piyungan Bapak Janan Sarjito, S.Ag pada saat observasi. Beliau juga menuturkan bahwa dua kelas siswa satu kelas diantaranya rata-rata berasal dari keluarga menengah ke bawah yang tidak mampu membayar SPP sekolah. Jika dirata-rata hanya $20 \%$ siswa yang mampu membayar SPP tepat waktu, selebihnya memilih untuk tidak sekolah jika terus-menerus ditagih SPP. Beberapa dari siswa ada yang membayar setahun sekali saat sawah orang tua mereka panen, itu pun dengan menawar jumlah tagihan SPP.

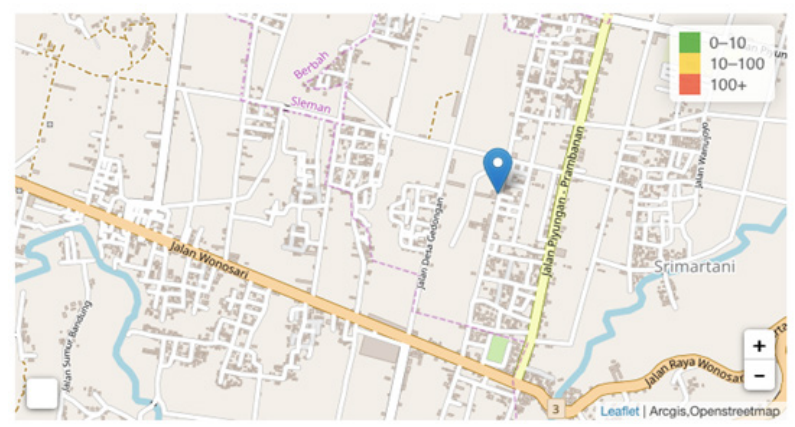

Gambar 1. Peta Lokasi SMA Muhammadiyah Piyungan

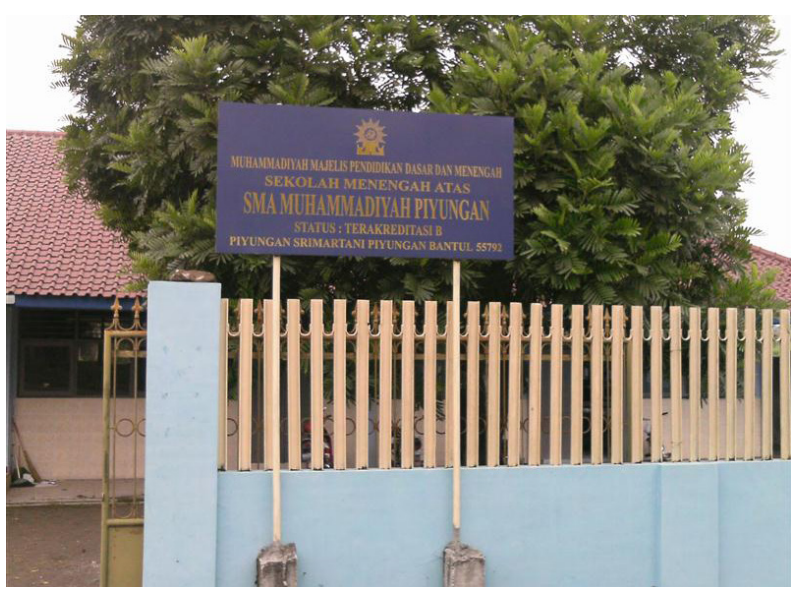

Gambar 2. Tampak Depan SMA Muhammadiyah Piyungan

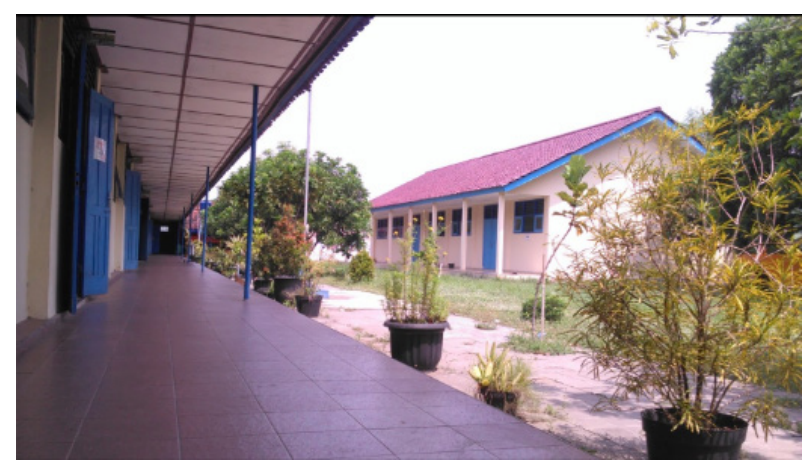

Gambar 3. Gedung Sekolah SMA Muhammadiyah Piyungan

Tabel 1. Jumlah Siswa Baru sebelum Pandemi Covid-19

\begin{tabular}{lll}
\hline 1 & $2017 / 2018$ & 17 Siswa \\
2 & $2018 / 2019$ & 30 Siswa \\
\hline
\end{tabular}

Kondisi ini berdampak pada beban pengelolaan sekolah yang berat, di mana hingga saat ini hanya mampu menyediakan 6 guru tetap sementara untuk kebutuhan guru lainnya dipenuhi dari guru lepas yang memiliki home base di sekolah lain. Melihat peta persaingan yang memojokan sekolah swasta, guru-guru di SMA Muhammadiyah Piyungan mencoba menangkap peluang baru yaitu siswa luar kota yang ingin bersekolah di Yogyakarta. Citra kota pendidikan telah menjadi magnet yang menarik lulusan dari luar kota bahkan dari luar Pulau Jawa untuk mengenyam pendidikan di kota ini.

Peluang ini diperkuat dengan pernyataan dari Kepala Disdikpora DIY Kadarmanta Baskara Aji bahwa 50\% siswa sekolah swasta di Yogyakarta berasal dari luar kota. Sekolah swasta yang memiliki kekhasan banyak diminati sebagai tempat menuntut ilmu. Berdasarkan identifikasinya wilayah yang memiliki siswa terbesar berasal dari luar DIY adalah Kota Yogyakarta dan Sleman. Di Kota Yogyayakarta seperti SMA Stella Duce, SMA Muhammadiyah 1, sedangkan di Sleman paling dominan ada di SMA de Britto (Wahyudi, 2019). 


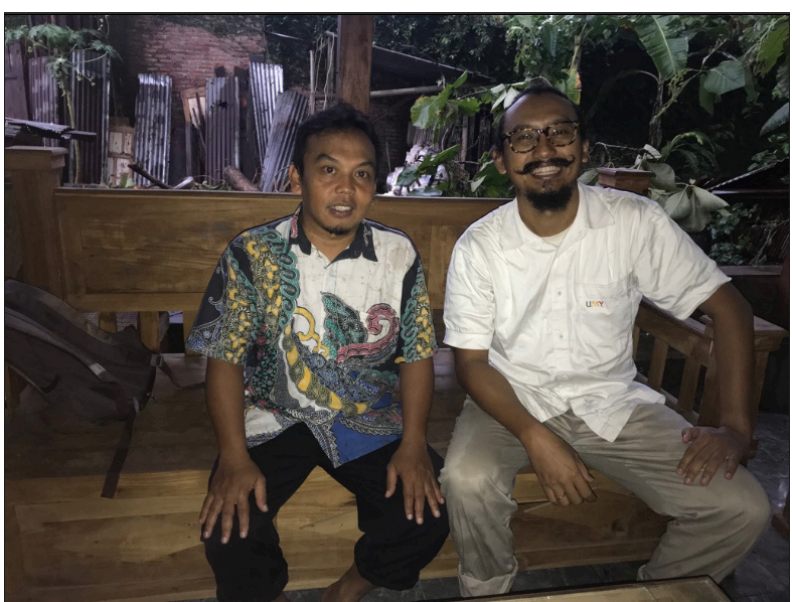

Gambar 4. Kepala Sekolah SMU Muhammadiyah Piyungan

Oleh karena itu guru-guru pengelola SMA Muhammadiyah Piyungan berinisiatif untuk mengubah format sekolah mereka agar memiliki kekhasan, yaitu sebagai Muhammadiyah Boarding School untuk menyasar target siswa dari luar kota. Hingga saat ini proses pengembangan menuju format baru didukung penuh oleh Muhammadiyah Boarding School Kalasan yang telah lebih dahulu berdiri. Pak Janan mengutarakan kendala yang saat ini mereka hadapi adalah cara berkomunikasi secara digital untuk memasarkan format baru sekolahnya, karena timnya saat ini adalah guruguru yang tidak memiliki pengalaman membuat strategi komunikasi pemasaran digital.

Pada tahap observasi pelaksana dan mitra telah menentukan permasalahan yang akan diselesaikan melalui program pengabdian kemitraan masyarakat adalah minimnya kemampuan guru untuk membuat konten, mengelola web, dan sosial media yang bertujuan untuk memasarkan sekolah pada siswa baru.

Dalam upaya menyelesaikan permasalahan mitra yang sudah dirumuskan di atas, maka kami merencanakan solusi peningkatan kemampuan guru dalam membuat konten dan mengelola web serta sosial media yang bertujuan untuk memasarkan sekolah pada siswa baru.

\section{METODE}

Solusi yang sudah kami rencanakan bagi mitra akan direalisasikan pada tahapan sebagai berikut :

a. Observasi dan perencanaan

Observasi bertujuan untuk menggali kondisi umum dari permasalahan pengelolaan komunikasi MBS Piyungan di sosial media yang kami lakukan dengan melakukan Focus Group Discussion dengan pengelola MBS Piyungan.

b. $\quad$ Pre Test

Tahap ini dilakukan untuk mengukur pemahaman dan kemampuan guru-guru SMA MBS piyungan dalam membuat konten dan mengelola web dan sosial media. Tes dilakukan melalui survey online di mana hasilnya akan dijadikan landasan untuk menyusun materi pembelajaran

c. Pembangunan Infrastruktur Digital

Website sebagai wadah informasi resmi di media digital disusun melalui tahap penggalian informasi promosi pendaftaran siswa baru dan informasi profil SMA MBS Piyungan. Setelah itu data promosi dan profil akan diolah menjadi tampilan web oleh programmer.

d. Pelaksanaan edukasi

Edukasi peningkatan kemampuan membuat konten dan mengelola web dan sosial media dilakukan pada 28 Juni 2020 di SMA Muhammadiyah Piyungan pukul 09.00 hingga 12.00

Tabel 2. Metode Pelaksanaan Kegiatan

\begin{tabular}{|c|c|c|c|}
\hline No & Bentuk Kegiatan & Tujuan & Pemateri \\
\hline 1 & $\begin{array}{lll}\text { Pelatihan pengelolaan } & \text { web, } \\
\text { pembuatan } & \text { konten statis dan } \\
\text { dinamis } & & \end{array}$ & $\begin{array}{l}\text { Memberikan pengetahuan } \\
\text { untuk menyediakan informasi } \\
\text { di media digital. }\end{array}$ & M. Sani Suprayogi, M.Cs \\
\hline 2 & $\begin{array}{l}\text { Pelatihan pengelolaan sosial } \\
\text { media, pembuatan redaksional } \\
\text { konten dan konten }\end{array}$ & & \\
\hline
\end{tabular}



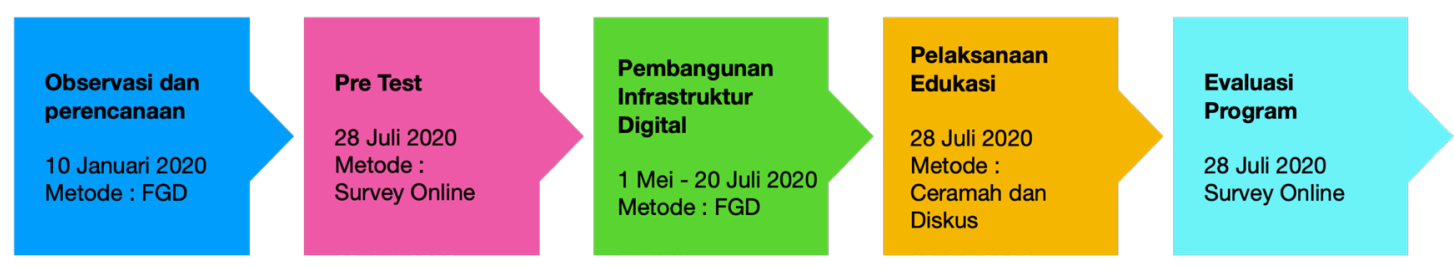

Diagram 1. Tahapan Pelaksanaan Kegiatan

\section{e. Evaluasi program}

Bertujuan untuk melihat dampak dari solusi yang kami tawarkan melalui post test, dilakukan secara online. Kemudian data post test dan pre test akan dibandingkan untuk melihat capaian pembelajaran dari guru-guru.

\section{HASIL DAN PEMBAHASAN}

Untuk menyelesaikan masalah minimnya kemampuan guru dalam pembuatan konten dan pengelolaan web serta sosial media yang bertujuan untuk memasarkan sekolah pada siswa baru. Tim Pengabdian masyarakat Ilmu Komunikasi Universitas Muhamadiyah Yogyakarta, yang diketuai oleh Erwan Sudiwijaya, MBA., MA dari Ilmu Komunikasi UMY kemudian mulai melaksanakan program pengabdian masyarakat sejak Desember hingga Juli 2020. Program pengabdian ini memiliki misi untuk membangun strategi komunikasi pemasaran di media digital antara sekolah dengan calon siswa, siswa, alumnus, dan orang tua. Komunikasi pemasaran adalah sarana yang digunakan perusahaan untuk memberikan informasi, membujuk, dan mengingatkan konsumen secara langsung atau tidak langsung tentang produk dan merek yang mereka jual. Dalam arti tertentu, komunikasi pemasaran mewakili "suara" perusahaan dan mereknya dan merupakan sarana yang dapat digunakan untuk membangun dialog dan membangun hubungan dengan konsumen (Kotler, 2013). Penggunaan media digital pada PPDB di SMPN 10 Solo yang digagas oleh tim pengabdian masyarakat Fakultas Teknik Universitas Muhammadiyah Surakarta terbukti berhasil diimplementasikan (Supriyono, 2019). Kemampuan web dalam media promosi yaitu untuk mendidik (Yunus, 2018), berinteraksi dengan promosi penjualan (Wiranata, 2020), menarik perhatian dan minat (Adhanisa, 2017), digunakan untuk memperluas cakupan global (Wahyudianarta, 2017), diakses melalui media seluler (Stephan, et al., 2015). Website disarankan berfokus pada penyebaran informasi (Li, Wang, \& Yu, 2015) menghambat promosi saat kekurangan konten (Król, 2019)

Proses komunikasi pemasaran melibatkan empat komponen komunikasi, komponen utamanya adalah pengirim dan penerima, lalu komponen alat komunikasi yaitu pesan dan media. Komponen fungsi komunikasi yaitu proses encoding, decoding, respon, dan umpan balik. Komponen terakhir adalah noise (pesan acak yang dapat mengganggu komunikasi).

Faktor kunci dalam komunikasi adalah pengirim harus mengetahui siapa audiens apa yang akan dijangkau dan tanggapan apa yang ingin mereka dapatkan. Mereka harus menyandikan pesan mereka sehingga audiens target dapat memecahkan kodenya. Mereka harus mengirimkan pesan melalui media yang menjangkau khalayak sasaran dan mengembangkan saluran umpan balik untuk memantau tanggapan. Semakin banyak kesamaan pengalaman antar pengirim dengan penerima, maka pesan akan semakin efektif.

Untuk meningkatkan peluang kampanye komunikasi pemasaran yang sukses, pemasar harus berusaha meningkatkan kemungkinan terjadinya setiap langkah. Misalnya, dari sudut pandang periklanan, kampanye iklan yang ideal akan memastikan bahwa konsumen yang tepat dihadapkan pada pesan yang tepat di tempat dan waktu yang tepat. Iklan tersebut menyebabkan konsumen memperhatikan iklan tersebut tetapi tidak mengganggu pesan yang dimaksud. Iklan tersebut dengan tepat mencerminkan tingkat pemahaman dan perilaku konsumen terhadap produk dan merek. Iklan tersebut dengan benar memposisikan merek dalam hal poin perbedaan dan poin paritas yang diinginkan dan dapat disampaikan. Iklan tersebut memotivasi konsumen untuk mempertimbangkan pembelian merek. Iklan tersebut menciptakan asosiasi merek yang kuat dengan semua efek 
komunikasi yang disimpan ini sehingga dapat berdampak saat konsumen mempertimbangkan untuk melakukan pembelian. (Kotler, 2013)

Selain iklan, komunikasi pemasaran juga melibatkan tujuh bauran komunikasi pemasaran lainnya yang saling bekerja sama yaitu

1. Advertising sebagai segala bentuk presentasi nonpersonal dan promosi ide, barang, atau layanan berbayar oleh sponsor yang teridentifikasi

2. Sales Promotion adalah berbagai insentif jangka pendek untuk mendorong percobaan atau pembelian produk atau layanan.

3. Event \& Experience adalah kegiatan dan program yang disponsori perusahaan yang dirancang untuk menciptakan interaksi terkait merek harian atau khusus

4. Public Relations and Publicity adalah berbagai program yang dirancang untuk mempromosikan atau melindungi citra perusahaan atau produk individualnya. Direct Marketing merupakan penggunaan surat, telepon, faks, email, atau internet untuk berkomunikasi secara langsung dengan atau meminta tanggapan atau dialog dari pelanggan dan prospek tertentu.

5. Interactive Marketing adalah aktivitas dan program online yang dirancang untuk melibatkan pelanggan atau prospek dan secara langsung atau tidak langsung meningkatkan kesadaran, meningkatkan citra, atau memperoleh penjualan produk, dan layanan.

6. Word of Mouth Marketing merupakan komunikasi lisan, tertulis, atau elektronik orang-ke-orang yang berhubungan dengan manfaat atau pengalaman membeli atau menggunakan produk atau layanan.

7. Personal Selling adalah interaksi tatap muka dengan satu atau lebih calon pembeli untuk tujuan membuat presentasi, menjawab pertanyaan, dan mendapatkan pesanan (Kotler, 2013).

Tahapan pengembangan komunikasi yang efektif

Untuk mencapai rencana pengembangan sekolah, SMA Muhammadiyah Piyungan menggandeng tim pengabdian masyarakat
Ilmu Komunikasi Universitas Muhamadiyah Yogyakarta, melalui program Pengabdian Masyarakat yang didanai Lembaga Penelitian, Publikasi, dan Pengembangan Masyarakat Universitas Muhamadiyah Yogyakarta. Tim yang diketuai oleh Erwan Sudiwijaya, MBA., MA dari Ilmu Komunikasi UMY kemudian mulai melaksanakan program pengabdian masyarakat sejak Desember 2019 hingga Juli 2020. Erwan menjelaskan bahwa program pengabdian ini memiliki misi untuk membangun strategi komunikasi di media digital antara sekolah dengan calon siswa, siswa, alumnus, dan orang tua siswa. Berikut adalah tahapan pelaksanaan komunikasi pemasaran digital di SMA Muhammadiyah Piyungan.

1. Identifikasi Target Audiens

Proses komunikasi pemasaran harus dimulai dengan target audiens yang jelas (Kotler, 2013) oleh karena itu Kepala Sekolah SMA Muhammadiyah Piyungan Janan Sarjito, S.Ag menuturkan bahwa jumlah siswa yang diterima tahun ini hanya berjumlah 20 siswa sehingga Ia berharap semoga promosi digital ini dapat memperluas pangsa pasar hingga luar Pulau Jawa.

2. Tentukan Tujuan Komunikasi

Kategori Kebutuhan, menetapkan kategori produk atau layanan yang diperlukan untuk menghilangkan ketidaksesuaian antara keadaan motivasi saat ini dan keadaan emosi yang diinginkan (Kotler, 2013). Pengelola SMA Muhammadiyah Piyungan berinisiatif untuk mengubah format sekolah mereka agar memiliki kekhasan, sekaligus positioning yaitu sebagai Muhammadiyah Boarding School. Oleh karena itu komunikasi pemasaran ditujukan untuk meningkatkan kesadaran merek pada positioning baru dari SMA Muhammadiyah Piyungan. Sehingga diharapkan target audiens memiliki kemampuan untuk mengidentifikasi merek dalam kategori.

3. Mendesain Komunikasi

Merumuskan komunikasi untuk mencapai respons yang diinginkan akan membutuhkan penyelesaian atas tiga poin berikut: apa yang harus dikatakan (strategi pesan), bagaimana mengatakannya 
(strategi kreatif), dan siapa yang harus mengatakannya (sumber pesan).

a. Strategi pesan

Dalam menentukan strategi pesan, pencarian manajemen untuk daya tarik, tema, atau ide yang terkait dengan pemosisian merek dan membantu menetapkan titik-titik paritas atau titik perbedaan. Beberapa di antaranya mungkin terkait langsung dengan kinerja produk atau layanan (kualitas, ekonomi, atau nilai merek), sedangkan yang lain mungkin terkait dengan pertimbangan yang lebih ekstrinsik (merek sebagai kontemporer, populer, atau tradisional) (Kotler, 2013). Kepala Sekolah SMAMuhammadiyah Piyungan Janan Sarjito, S.Ag menuturkan bahwa rencana pengembangan sekolah di tahun 2020 adalah mengembangkan sekolah menjadi Muhammadiyah Boarding School pada level SMA untuk melengkapi layanan SMA reguler yang sudah ada. Oleh karena itu kami menetapkan pesan dalam komunikasi pemasarannya adalah Muhammadiyah Boarding School pada level SMA untuk melengkapi layanan SMA reguler yang sudah ada.

b. Strategi kreatif

Efektivitas komunikasi bergantung pada bagaimana pesan diekspresikan, serta pada isi pesan itu sendiri. Jika komunikasi tidak efektif, itu mungkin berarti pesan yang digunakan salah, atau pesan yang benar diungkapkan dengan buruk. Strategi kreatif adalah cara pemasar menerjemahkan pesan mereka ke dalam komunikasi tertentu. Kita dapat mengklasifikasikannya secara luas sebagai daya tarik informasi atau transformasi (Kotler, 2013). Strategi kreatif SMA Muhammadiyah Piyungan menggunakan pendekatan informasi di mana daya tarik informasi ini akan menguraikan atribut atau manfaat dari layanan Muhammadiyah Boarding School melalui media Website.
4. Saluran Komunikasi

Media digital yang digunakan pada komunikasi pemasaran SMA Muhammadiyah Piyungan memiliki karakter trough the line, yaitu memiliki fungsi komunikasi massa seperti yang dimiliki media above the line sekaligus juga memiliki fungsi komunikasi personal seperti yang dimiliki media below the line. Developer Website M. Sani Suprayogi, M.Cs mendesain Website SMU Muhammadiyah Piyungan yang terintegrasi dengan Instagram. Sehingga fungsi Website yang dikenal sebagai rumah informasi di media digital dapat dipadukan dengan interaksi personal dari sosial media. Karakter media digital SMA Muhammadiyah Piyungan memiliki kemampuan komunikasi personal yang memungkinkan dua atau lebih orang berkomunikasi tatap muka, orang-keorang. Pesan instan dan situs independen untuk mengumpulkan ulasan konsumen adalah saluran lain, salah satu saluran yang semakin penting dalam beberapa tahun terakhir. Saluran komunikasi personal memperoleh keefektifannya melalui presentasi dan umpan balik individual. Sekaligus komunikasi non personal sebagai komunikasi yang diarahkan ke lebih dari satu orang dan mencakup media, promosi penjualan, acara, pengalaman, serta hubungan masyarakat.

5. Tetapkan Anggaran Komunikasi Pemasaran Total

Penetapan anggaran pada komunikasi pemasaran digital SMA Muhammadiyah Piyungan menggunakan metode tujuan dan tugas di mana tim pengabdian masyarakat Ilmu Komunikasi Universitas Muhamadiyah Yogyakarta diminta untuk mengembangkan anggaran promosi dengan menentukan tujuan spesifik yaitu untuk meningkatkan kesadaran merek pada positioning baru dari SMA Muhammadiyah Piyungan. Menentukan tugas yang harus dilakukan untuk mencapai tujuan ini, dan memperkirakan biaya untuk melakukan tugas ini. Jumlah biaya ini adalah anggaran promosi yang diusulkan pada Lembaga Penelitian, Publikasi, dan Pengembangan 
Masyarakat Universitas Muhamadiyah Yogyakarta.

6. Menentukan Bauran Komunikasi Pemasaran

Tim promosi SMA Muhammadiyah Piyungan bersama tim pengabdian masyarakat Ilmu Komunikasi Universitas Muhamadiyah Yogyakarta lalu mengalokasikan anggaran komunikasi pemasaran untuk hubungan masyarakat dan publisitas, pemasaran interaktif dan pemasaran dari mulut ke mulut. Ketiga fungsi ini dilakukan melalui media Website yang terintegrasi dengan sosial media.

7. Mengelola Proses Komunikasi Pemasaran Terpadu

Media koordinasi dapat terjadi lintas dan dalam jenis media, tetapi pemasar harus menggabungkan saluran komunikasi pribadi dan nonpribadi untuk mencapai dampak yang maksimal (Kotler, 2013). Kamipun mengembangkan inovasi untuk menggabungkan Website dengan sosial media yang dapat di-update dengan mudah mengacu pada pengabdian masyarakat Universitas Muhammadiyah Surakarta dengan menggunakan blog yang mudah dioperasikan untuk membangun Website di PCM Baki (Anggoro, Yuniar, \& Widyanti, 2019). Penerapan strategi komunikasi pemasaran dilakukan dengan

a. Menggali data, mengolah dan menyusun Website yang dilakukan. Secara lebih detil anggota tim pengabdian Ilmu Komunikasi Universitas Muhamadiyah Yogyakarta Ayu Amalia, M.Si menuturkan bahwa penyusunan Website sekolah didesain agar dapat di-update dengan mudah, oleh karena itu website https://smapiyunganmbs. sch.id/ dapat di-update dengan mudah melalui Instagram.

b. Menggelar workshop pengelolaan Website dan beriklan di sosial media pada Selasa, 28 Juli 2020 di SMA Muhammadiyah Piyungan, Bantul, Yogyakarta. Workshop ini digelar sebagai langkah koordinasi agar tim promosi sekolah dapat langsung memanfaatkan Website dan mengoptimalkan sosial media. Pembicara workshop sekaligus Website developer M. Sani Suprayogi, M.Cs menyarankan penggunaan sosial media untuk memperkuat posisi sekolah agar tampak berbeda dari kompetitor sehingga dapat menjadi alasan bagi calon siswa dan orang tuanya untuk bersekolah di SMA Muhammadiyah Piyungan. Workshop yang dimulai pada pukul 10.00 ini dihadiri oleh enam guru muda di lingkungan SMA Muhammadiyah Piyungan dan berakhir pada jam 12.00.

c. Untuk menunjang pengelolaan Website dan sosial media, pada kesempatan ini tim pengabdian masyarakat dari Ilmu Komunikasi FISIP Universitas Muhamadiyah Yogyakarta juga menghibahkan satu set komputer all in one pada SMU Muhammadiyah Piyungan.

Pemilihan pendampingan secara langsung pada indikator peningkatan pengetahuan ini mengacu pada keberhasilan pendampingan Universitas Veteran Bangun Nusantara pada Coffeshop Cekopi pada indikator peningkatan pengetahuan sebesar >25\% (Insani, Wijayanti, \& Cahyaningrum, 2020).

Pelaksanaan pengabdian masyarakat di SMA Muhammadiyah Piyungan Kami laksanakan sebagai berikut

\section{a. Observasi dan perencanaan}

Observasi bertujuan untuk menggali kondisi umum dari permasalahan pengelolaan komunikasi MBS Piyungan di sosial media yang Kami lakukan dengan melakukan Focus Group Discussion dengan pengelola MBS Piyungan. Berdasarkan proses tersebut ditemukan bahwa :

Peraturan Mendikbud Nomor 51 tahun 2018 tentang PPDB (Penerimaan Peserta Didik Baru) pada pasal 16 menyebutkan bahwa pendaftaran PPDB dilaksanakan melalui jalur zonasi sebesar $90 \%$ dari daya tampung. Hal ini berimbas pada menurunnya jumlah pendaftar di SMA Muhammadiyah Piyungan, pada angka 20 siswa baru di tahun 2020 ini. Oleh karena itu 
guru-guru pengelola SMA Muhammadiyah Piyungan berinisiatif untuk mengubah format sekolah mereka agar memiliki kekhasan, yaitu sebagai Muhammadiyah Boarding School untuk menyasar target siswa dari luar kota.

Pandemi COVID-19 berdampak langsung pada menurunnya jumlah pendaftar di SMA Muhammadiyah Piyungan, salah satu penyebabnya ditengarai karena aktivitas promosi fisik yang menurun karena pemberlakukan pembatasan fisik. Permasalahan kendala komunikasi dengan calon siswa baru, membuat pengelola sekolah untuk memaksimalkan media digital yang selama ini sudah ada namun belum optimal.

b. $\quad$ Pre Test

Tahap ini dilakukan untuk mengukur pemahaman dan kemampuan guru-guru SMA MBS piyungan dalam membuat konten dan mengelola web dan sosial media. Tes dilakukan melalui survey online dan hasilnya akan dijadikan landasan untuk menyusun materi pembelajaran

Berdasarkan tabel pra survey di atas kesadaran bahwa berpromosi di Web dan sosial media sudah cukup tinggi. Namun responden baru menyatakan mampu melakukan promosi di sosial media sementara Website hanya 20\% yang mampu. Kemampuan menganalisa promosi digital di sosial media baru 20\% dan Web belum ada yang mengetahui, termasuk juga untuk memasang iklan di sosial media semua responden menyatakan belum mampu.

c. Pembangunan Infrastruktur Digital

Website sebagai wadah informasi resmi di media digital disusun melalui tahap penggalian informasi promosi pendaftaran siswa baru dan informasi profil SMA MBS Piyungan. Setelah itu data promosi dan profil akan diolah menjadi tampilan Web oleh programmer. Penerapan strategi komunikasi pemasaran dengan menggali data, mengolah, dan menyusun Website yang dilakukan. Secara lebih detail anggota tim pengabdian Ilmu Komunikasi Universitas Muhamadiyah Yogyakarta Ayu Amalia, M.Si menuturkan bahwa penyusunan Website sekolah didesain agar dapat di-update dengan mudah, oleh karena itu Website https://smapiyunganmbs.sch.id/ dapat diupdate dengan mudah melalui Instagram.

Tabel 3. Pre Test Tim Promosi SMU Muhammadiyah Piyungan

\begin{tabular}{lccc}
\hline & Pre Test & Pre Test & Pre Test \\
\hline & Menyadari & Sangat Menyadari & \\
\cline { 2 - 4 } $\begin{array}{l}\text { Apakah Anda menyadari manfaat Website sebagai } \\
\text { media promosi sekolah? }\end{array}$ & $40 \%$ & $60 \%$ & \\
$\begin{array}{l}\text { Apakah Anda menyadari manfaat sosial media } \\
\text { sebagai media promosi sekolah? }\end{array}$ & $40 \%$ & $60 \%$ & \\
\cline { 2 - 4 } & Belum Mampu & Ragu-ragu & Mampu \\
\cline { 2 - 4 } $\begin{array}{l}\text { Apakah Anda mampu menggunakan Website } \\
\text { sebagai media promosi sekolah? }\end{array}$ & $40 \%$ & $40 \%$ & $20,0 \%$ \\
$\begin{array}{l}\text { Apakah Anda mampu menggunakan sosial media } \\
\text { sebagai media promosi sekolah? }\end{array}$ & $0 \%$ & 0 & $100,0 \%$ \\
$\begin{array}{l}\text { Apakah Anda sudah mengetahui cara memasang } \\
\text { iklan di sosial media? }\end{array}$ & $40 \%$ & $60 \%$ & $0,0 \%$ \\
\cline { 2 - 4 } $\begin{array}{l}\text { Apakah Anda mampu memasang iklan di sosial } \\
\text { media }\end{array}$ & Belum Mengetahui & Ragu-Ragu & Mengetahui \\
\cline { 2 - 3 } $\begin{array}{l}\text { Apakah Anda sudah mengetahui cara menganalisa } \\
\text { iklan di sosial media? }\end{array}$ & $100 \%$ & 0 & $0,0 \%$ \\
$\begin{array}{l}\text { Apakah Anda mampu menganalisa iklan di sosial } \\
\text { media? }\end{array}$ & $20 \%$ & $60 \%$ & $20,0 \%$ \\
\hline
\end{tabular}




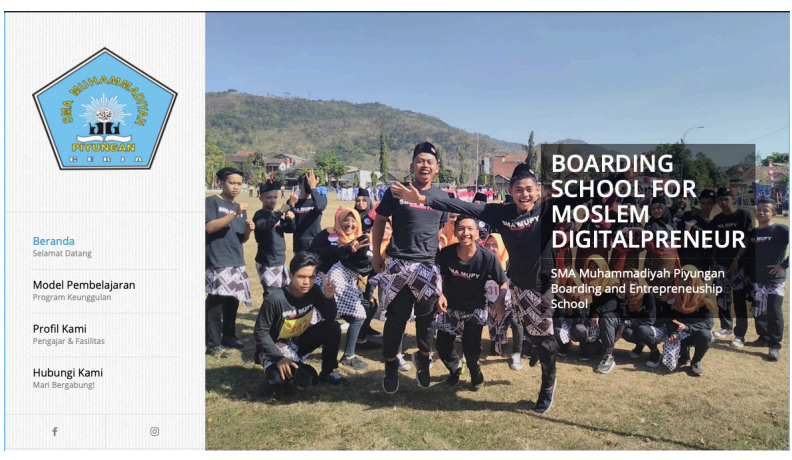

Gambar 5. Tampilan luaran program pengabdian berupa Website SMU

Muhammadiyah Piyungan

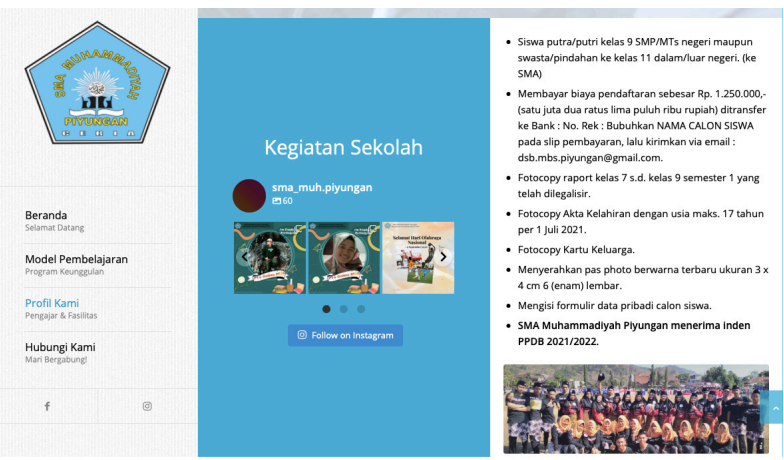

Gambar 6. Integrasi Instagram dan Website

d. Pelaksanaan edukasi

Edukasi peningkatan kemampuan membuat konten dan mengelola Web dan sosial media akan kami lakukan dengan workshop pengelolaan Website dan beriklan di sosial media pada Selasa, 28 Juli 2020 di SMA Muhammadiyah Piyungan, Bantul, Yogyakarta. Topik materi dari workshop ini adalah seputar cara meng-upload konten statis dan pengelolaan sosial media terutama Instagram yang terkoneksi sebagai konten dinamis di Web. Workshop ini digelar sebagailangkah koordinasiagar tim promosi sekolah dapat langsung memanfaatkan Website dan mengoptimalkan sosial media. Pembicara workshop sekaligus Website developer M. Sani Suprayogi, M.Cs menyarankan penggunaan sosial media untuk memperkuat posisi sekolah agar tampak berbeda dari kompetitor sehingga dapat menjadi alasan bagi calon siswa dan orang tua siswa untuk bersekolah di SMA Muhammadiyah Piyungan. Workshop yang dimulai pada pukul 10.00 ini dihadiri oleh enam guru muda di lingkungan SMA
Muhammadiyah Piyungan dan berakhir pada pukul 12.00. Diskusi pada workshop ini dipicu oleh pertanyaan peserta tentang proses pemasangan iklan di sosial media yang berkembang hingga strategi pemasangan konten di Instagram. Untuk menunjang pengelolaan Website dan sosial media, pada kesempatan ini tim pengabdian masyarakat dari Ilmu Komunikasi FISIP Universitas Muhamadiyah Yogyakarta juga menghibahkan satu set komputer all in one pada SMA Muhammadiyah Piyungan.

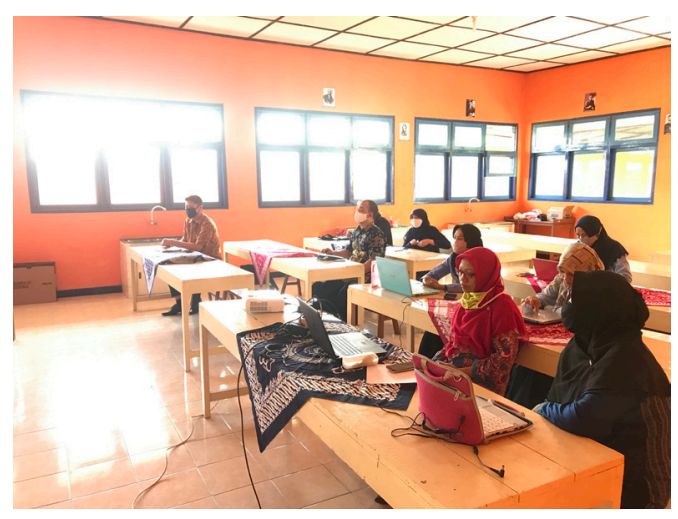

Gambar 7. Suasana Workshop



Gambar 8. Serah terima hibah satu set PC

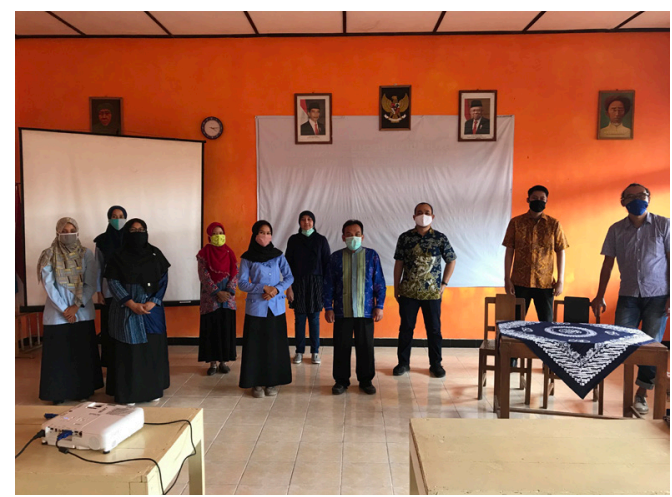

Gambar 9. Perserta, narasumber workshop dan tim pengabdian masyarakat 
e. Evaluasi program

Bertujuan untuk melihat dampak dari solusi yang kami tawarkan melalui post test, dilakukan secara online. Kemudian data post test dan pre test akan dibandingkan untuk melihat capaian pembelajaran dari guru-guru.

Setelah dilakukan serah terima pengelolaan Website dan workshop pengelolaan web dan beriklan di sosial media. Tampak peningkatan yang signifikan pada kemampuan pengelola promosi digital di SMA Muhammadiyah Piyungan. Jumlah responden yang menyadari pentingnya berpromosi di Web meningkat menjadi $71,4 \%$ dan $85,7 \%$, jumlah responden yang memiliki kemampuan mengelola website meningkat dari $20 \%$ menjadi $57,1 \%$ termasuk jumlah responden yang mampu memasang iklan kini sudah ada sebanyak 71,4\%. Pada kemampuan menganalisa iklan di sosial media pun terjadi peningkatan jumlah responden menjadi 57,1\%.

Program ini pun mendapat ekspos dari media yaitu Suara Muhammadiyah dan Website resmi Muhammadiyah

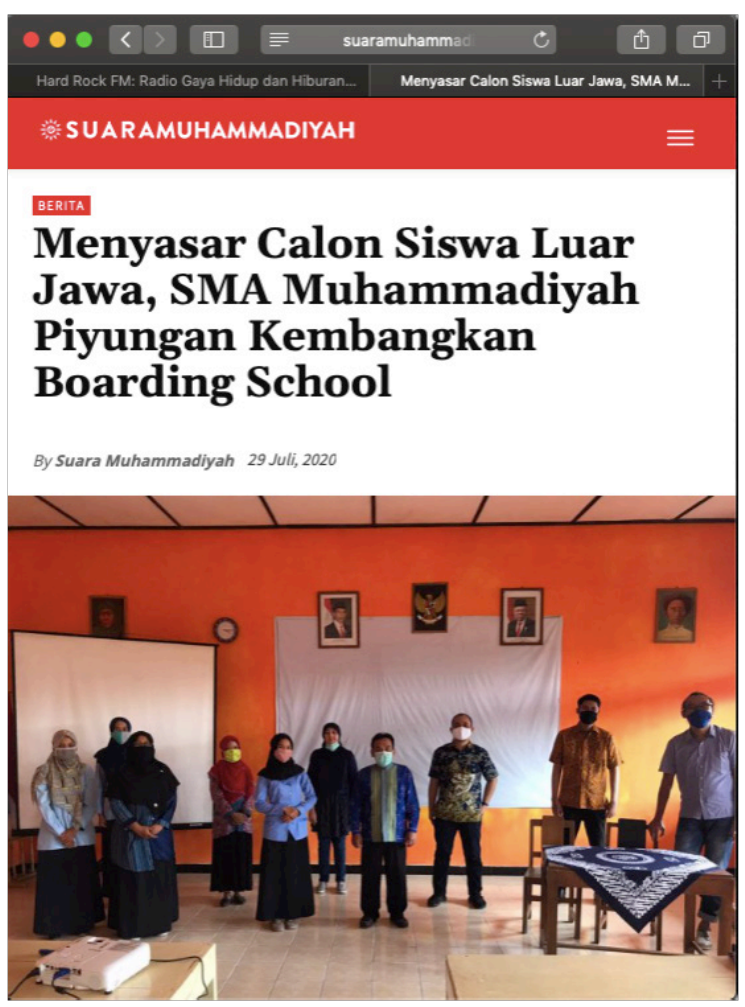

Gambar 10. Berita di Suara Muhammadiyah

Tabel. 4. Perbandingan Pre dan Post Test Tim Promosi SMA Muhammadiyah Piyungan

\begin{tabular}{|c|c|c|c|c|c|c|}
\hline & Pre Test & $\begin{array}{l}\text { Post } \\
\text { Test }\end{array}$ & Pre Test & $\begin{array}{l}\text { Post } \\
\text { Test }\end{array}$ & Pre Test & $\begin{array}{l}\text { Post } \\
\text { Test }\end{array}$ \\
\hline & \multicolumn{2}{|c|}{ Menyadari } & \multicolumn{2}{|c|}{ Sangat Menyadari } & & \\
\hline $\begin{array}{l}\text { Apakah Anda menyadari manfaat Website } \\
\text { sebagai media promosi sekolah? }\end{array}$ & $40 \%$ & $28,6 \%$ & $60 \%$ & $71,4 \%$ & & \\
\hline \multirow[t]{2}{*}{$\begin{array}{l}\text { Apakah Anda menyadari manfaat sosial } \\
\text { media sebagai media promosi sekolah? }\end{array}$} & $40 \%$ & $14,3 \%$ & $60 \%$ & $85,7 \%$ & & \\
\hline & \multicolumn{2}{|c|}{ Belum Mampu } & \multicolumn{2}{|c|}{ Ragu-ragu } & \multicolumn{2}{|c|}{ Mampu } \\
\hline $\begin{array}{l}\text { Apakah Anda mampu menggunakan } \\
\text { Website sebagai media promosi sekolah? }\end{array}$ & $40 \%$ & $14,3 \%$ & $40 \%$ & $28,6 \%$ & $20,0 \%$ & $57,1 \%$ \\
\hline $\begin{array}{l}\text { Apakah Anda mampu menggunakan sosial } \\
\text { media sebagai media promosi sekolah? }\end{array}$ & $0 \%$ & $14,3 \%$ & 0 & $14,3 \%$ & $100,0 \%$ & $71,4 \%$ \\
\hline \multirow[t]{2}{*}{$\begin{array}{l}\text { Apakah Anda sudah mengetahui cara } \\
\text { memasang iklan di sosial media? }\end{array}$} & $40 \%$ & $0,0 \%$ & $60 \%$ & $28,6 \%$ & $0,0 \%$ & $71,4 \%$ \\
\hline & \multicolumn{2}{|c|}{ Belum Mengetahui } & \multicolumn{2}{|c|}{ Ragu-Ragu } & \multicolumn{2}{|c|}{ Mengetahui } \\
\hline $\begin{array}{l}\text { Apakah Anda mampu memasang iklan di } \\
\text { sosial media? }\end{array}$ & $100 \%$ & $0,0 \%$ & 0 & $0,0 \%$ & $0,0 \%$ & $100,0 \%$ \\
\hline $\begin{array}{l}\text { Apakah Anda sudah mengetahui cara } \\
\text { menganalisa iklan di sosial media? }\end{array}$ & $20 \%$ & $14,3 \%$ & $60 \%$ & $28,6 \%$ & $20,0 \%$ & $57,1 \%$ \\
\hline $\begin{array}{l}\text { Apakah Anda mampu menganalisa iklan di } \\
\text { sosial media? }\end{array}$ & $40 \%$ & $14,3 \%$ & $60 \%$ & $28,6 \%$ & $0,0 \%$ & $57,1 \%$ \\
\hline
\end{tabular}




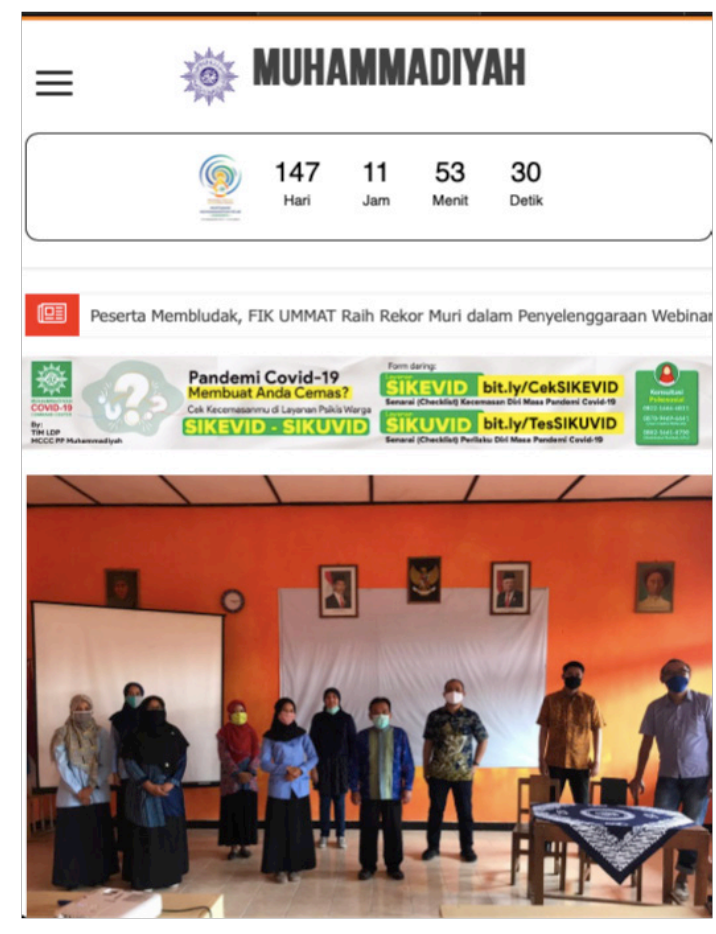

Gambar 11. Berita di web Muhammadiyah

\section{SIMPULAN}

Hasil dari pengabdian masyarakat ini adalah tersusunnya strategi komunikasi pemasaran digital bagi SMA Muhammadiyah Piyungan dalam bentuk Website yang terintegrasi dengan sosial media Instagram. Pengelola pun telah dibekali dengan workshop pengelolaan Website dan beriklan di sosial media serta hibah satu set komputer sebagai alat penunjang operasional pengelolaan komunikasi pemasaran digital.

Rencana monitoring strategi sosial media dan pengelolaan website di SMU Muhammadiyah Piyungan akan dilakukan dengan pembuatan Whatsapp Grup, merupakan forum diskusi yang berisi guru pengelola sosial media, developer $w e b$ dan pelaksana pengabdian masyarakat dari UMY. Forum ini berfungsi untuk memberikan masukan pada pembuatan konten yang akan diupload.

\section{PERSANTUNAN}

Tim pengabdian masyarakat Ilmu Komunikasi UMY menghaturkan terima kasih yang sebesar-besarnyakepada RektorUniversitas Muhammadiyah Yogyakarta, Lembaga Penelitian dan Pengembangan Masyarakat Universitas Muhammadiyah Yogyakarta, Kepala Sekolah, guru, dan staf di SMA Muhammadiyah Piyungan dan Web Developer M. Sani Suprayogi, M.Cs yang telah bekerja sama untuk mewujudkan strategi komunikasi pemasaran digital bagi SMA Muhammadiyah Piyungan.

\section{REFERENSI}

Kompasiana.com. (2019, June 9). Retrieved October 1, 2020, from https://www.kompasiana.com/ deviniq/5d03e485c01a4c4a0855d7b9/sistem-zonasi-melumpuhkan-sekolah-swasta?page=all.

Kusdiyanto, Y. (2020, May 20). Harianjogja.com. Retrieved October 1, 2020, from https://jogjapolitan. harianjogja.com/read/2019/05/20/513/993450/sistem-zonasi-tak-untungkan-sekolahswasta

Wijayanti, M. P., \& Nurjaman, A. (2020). Analisis Implementasi Kebijakan Sistem Zonasi PPDB sebagai Upaya Pemerataan Pendidikan Sekolah Menengah Atas di Daerah Istimewa Yogyakarta. Jurnal Kebijakan Dan Pengembangan Pendidikan , 8 (1).

Wahyudi, A. (2019, March 14). Sistem Zonasi SMA/SMK Swasta di Yogyakarta Sulit Diterapkan. Retrieved November 1, 2020, from https://kumparan.com/tugujogja/sistem-zonasi-sma-smk-swasta-diyogyakarta-sulit-diterapkan-1533808473208081652

Kotler, P. \&. (2013). Marketing management. Harlow: Pearson Education.

Supriyono, H. B. (2019). Website Sekolah untuk Menunjang Penerimaan Peserta Didik Baru di SMP Muhammadiyah 10 Surakarta. Warta LPM, 21 (2).

Yunus, U. A. (2018). Usability Testing of Indonesia Tourism Promotion Website. Journal of Physics: Conference Series, 978 ( 012007). 
Wiranata, A. T. (2020). Do Website Quality, Fashion Consciousness, and Sales Promotion Increase Impulse Buying Behavior of E-Commerce Buyers?

Adhanisa, C. \&. (2017). The Effectiveness of The Website And Instagram as a Means of Promotion in Community Based Tourism Area. 1 (4), 451.

Wahyudianarta, P. S. (2017). The Development of Website Media on Smartphone Products as an Online Promotion Tool in Facing the Global Marketing Era. . International Journal of Academic Research in Business and Social Sciences , 7 (6).

Stephan, G. H., Stephan, G., Hoyt, M. J., Storm, D. S., Shirima, S., Matiko, C., et al. (2015). Development and promotion of a National Website to Improve Dissemination of information Related to the Prevention of Mother-to-child HIV Transmission (PMTCT) in Tanzania. BMC Public Health , 15 (1).

Li, X., Wang, Y., \& Yu, Y. (2015). Present and Future Hotel Website Marketing Activities: Change Propensity Analysis. International Journal of Hospitality Management , 47, 131 - 139.

Król, K. (2019). Forgotten agritourism: Abandoned Websites in the Promotion of Rural Tourism in Poland. Journal of Hospitality and Tourism Technology, 10 (3), 431 - 442.

Anggoro, D. A., Yuniar, A. E., \& Widyanti, T. N. (2019). Pelatihan Pembangunan Website Informasi di Pimpinan Cabang Muhammadiyah Baki, Sukoharjo. Warta LPM , 22 (2), 59-66.

Insani, S. F., Wijayanti, A. W., \& Cahyaningrum, B. N. (2020). Pendampingan Pelaksanaan Survey Kepuasan Pelanggan pada Coffee Shop Cekopi di Mendungan, Kartasura. Warta LPM , 23 (2), 94104. 